\title{
Ethanol Effects on N-Methyl-D-Aspartate Receptors in the Bed Nucleus of the Stria Terminalis
}

\author{
Tiffany A. Wills ${ }^{1}$ and Danny G. Winder ${ }^{1,2,3}$ \\ ${ }^{1}$ Department of Molecular Physiology and Biophysics, Vanderbilt University School of Medicine, \\ Nashville, Tennessee 37232-0615 \\ ${ }^{2}$ Center for Molecular Neuroscience, Vanderbilt University School of Medicine, Nashville, Tennessee \\ 37232-0615 \\ ${ }^{3}$ J.F. Kennedy Center for Research on Human Development, Vanderbilt University School of Medicine, \\ Nashville, Tennessee 37232-0615 \\ Correspondence: danny.winder@vanderbilt.edu
}

\begin{abstract}
The extended amygdala is a series of interconnected, embryologically similar series of nuclei in the brain that are thought to play key roles in aspects of alcohol dependence, specifically in stress-induced increases in alcohol-seeking behaviors. Plasticity of excitatory transmission in these and other brain regions is currently an intense area of scrutiny as a mechanism underlying aspects of addiction. $\mathrm{N}$-methyl-D-aspartate (NMDA) receptors (NMDARs) play a critical role in plasticity at excitatory synapses and have been identified as major molecular targets of ethanol. Thus, this article will explore alcohol and NMDAR interactions first at a general level and then focusing within the extended amygdala, in particular on the bed nucleus of the stria terminalis (BNST).
\end{abstract}

$\mathrm{D}_{\mathrm{a}}^{\mathrm{u}}$ uring the transition to ethanol dependence, a shift is thought to occur in the motivational drive for ethanol use. The beginning stages of ethanol use are thought to be driven primarily by the positive reinforcing effects of ethanol (pleasurable effects from ethanol). However, as addiction progresses, it is thought that the negative reinforcing properties of the ethanol (withdrawal/negative affect) are a major motivational force behind compulsive ethanol intake (Koob and Le Moal 1997). This increased negative affect (depression and anxiety) that accompanies ethanol withdrawal (De Soto et al. 1985; Roelofs 1985) is cited as an important contributor to relapse in alcoholics and is known to persist long after the outwardly physical symptoms of withdrawal have dissipated (Hershon 1977; Begleiter and Porjesz 1979; Roelofs 1985; Grant et al. 1987). One factor that is likely to contribute to the manifestation of negative affect during withdrawal is stress. Both clinical and animal studies have illustrated that stress during withdrawal increases the risk of relapse in dependent subjects (Le et al. 2000; Sinha 2001). The extended amygdala is an area of the brain thought to be a key player in these withdrawal-related behaviors.

Editors: R. Christopher Pierce and Paul J. Kenny

Additional Perspectives on Addiction available at www.perspectivesinmedicine.org

Copyright (C) 2013 Cold Spring Harbor Laboratory Press; all rights reserved; doi: 10.1101/cshperspect.a012161

Cite this article as Cold Spring Harb Perspect Med 2013;3:a012161 
T.A. Wills and D.G. Winder

The extended amygdala is a series of interconnected, embryologically similar nuclei in the brain that are thought to play key roles in aspects of alcohol dependence, specifically in stress-induced increases in alcohol-seeking behaviors (reviewed in McCool 2011 and Wills et al. 2012). Plasticity of excitatory transmission in these and other brain regions is currently an intense area of scrutiny as a mechanism underlying aspects of addiction. NMDA receptors (NMDARs) play a critical role in plasticity at excitatory synapses (de Marchena et al. 2008), and have been identified as major molecular targets of ethanol. Thus, this article will explore alcohol and NMDAR interactions first at a general level, and then focusing within the extended amygdala, in particular on the bed nucleus of the stria terminalis (BNST).

\section{ACUTE ETHANOL EFFECTS ON NMDARs}

Seminal studies by several laboratories have shown that physiologically relevant ethanol concentrations $(25-100 \mathrm{~mm})$ potently inhibit NMDARs (Dildy and Leslie 1989; Hoffman et al. 1989; Lovinger et al. 1989) and modulate NMDAR plasticity in several brain regions (Blitzer et al. 1990; Morrisett and Swartzwelder 1993; Givens and McMahon 1995; Grover and Frye 1996; Schummers and Browning 2001; Hendricson et al. 2002; Weitlauf et al. 2004; Izumi et al. 2005). The NMDAR is a heterotetrameric complex composed of two obligatory GluN1 subunits and two GluN2 or GluN3 subunits. Numerous subunit combinations are possible with eight different variations of GluN1 subunit and four distinct GluN2 subunit isoforms (A, B, $\mathrm{C}$, and D). However, the NMDARs primarily expressed in the adult forebrain are composed of GluN2A and/or GluN2B subunits. A large body of work has been conducted to determine ethanol's actions on specific subunits of the NMDAR complex.

\section{GluN1}

The GluN1 subunit is an obligate subunit of the NMDAR and is, therefore, a likely target for the inhibitory effects of ethanol. There are eight possible variations of the GluN1 subunit produced through alternative splicing (four sites on the carboxyl terminus and two sites on the amino terminus). This carboxyl terminus of the GluN1 subunit is composed of four cassettes (C0, C1, C2, and $\mathrm{C} 2$ ) but the $\mathrm{C} 0$ cassette is conserved within all splice variants. Removal of this $\mathrm{C} 0$ cassette decreases ethanol inhibition of NMDARs (Anders et al. 2000). The C0 cassette was also found to be critical for the $\mathrm{Ca}^{2+}$ sensitive modulation of ethanol inhibition on NMDARs (Mirshahi and Woodward 1995; Mirshahi et al. 1998). Interestingly, the ethanol sensitivity of this C0 cassette was only found in conjunction with the GluN2A subunit (Mirshahi et al. 1998; Anders et al. 2000). Evidence also suggests that several phosphorylation sites in the $\mathrm{C} 1$ cassette region can modulate ethanol sensitivity as well, but again these effects are selective for GluN2A-containing NMDARs (Xu et al. 2011). Further, sites within the transmembrane regions (TM) of the GluN1 and GluN2A subunits have been investigated for the effects of ethanol. Several mutations in the GluN1 subunit (TM3 F637, F639; TM4 M813; TM4 L819) and GluN2A subunit (TM4 M832) have been found to alter ethanol sensitivity (Ronald et al. 2001; Ren et al. 2003; Honse et al. 2004; Smothers and Woodward 2006; Ren et al. 2007).

\section{GluN2}

As shown above, ethanol sensitivity is partially regulated by GluN1, but this sensitivity was only seen in conjunction with the GluN2A subunit suggesting subunit combinations are critical (Mirshahi et al. 1998; Anders et al. 2000; Xu et al. 2011). The GluN2 subunit has four isoforms (A, B, C, and D) but the NMDARs primarily expressed in the adult forebrain are composed of GluN2A and/or GluN2B subunits. These GluN2 subunits dictate many channel properties such as decay time, localization, intracellular signaling, and conductance (CullCandy et al. 2001; Traynelis et al. 2010).

Investigations on GluN2 subunit selectivity of ethanol have been performed in mammalian heterologous expression systems such as HEK cells and Xenopus oocytes expressing recombi- 
nant NMDARs. In HEK cells, some studies find equal ethanol inhibition in GluN1/GluN2A, GluN1/GluN2B, GluN1/GluN2A/GluN2B subunit combinations (Lovinger 1995; Blevins et al. 1997; Popp et al. 1998; Anders et al. 1999a,b), whereas GluN1/GluN2B-containing receptors seem to be slightly more sensitive in other studies (especially at low ethanol doses) (Lovinger 1995; Blevins et al. 1997; Anders et al. 1999b). This greater sensitivity of GluN1/GluN2B-containing receptors was not seen when Xenopus oocytes were used (Kuner et al. 1993; Masood et al. 1994; Chu et al. 1995; Mirshahi and Woodward 1995). Later work confirmed this finding, showing that GluN2B-containing receptors were more ethanol sensitive but that the differences in sensitivity between GluN2A and B were greatly dependent on the expression system used (Smothers et al. 2001). These GluN2Aand GluN2B-containing receptors, however, were much more sensitive than their GluN2Cor GluN2D-containing counterparts (Chu et al. 1995; Mirshahi and Woodward 1995). In recent work, an extensive evaluation of the acute effects of ethanol in HEK cells with all combinations of the eight GluN1 isoforms and four GluN2 subunits was performed. Ethanol inhibition was greater in GluN2B subunits than in GluN2A and when coupled with GluN1-1a, 3a, 4a. However, there was no difference in ethanol inhibition when GluN2B and GluN2A were coupled with GluN1-2a, 1-4b (Jin and Woodward 2006).

Another commonly used technique to evaluate the GluN2B subunit specificity of ethanol inhibition has been with the use of ifenprodil and its derivatives (GluN2B-selective antagonists). In a number of brain regions (hippocampus, cerebellum, vBNST, CeA, lateral septum, cortex), these drugs are able to attenuate the inhibitory effects of acute ethanol (Lovinger 1995; Fink and Gothert 1996; Engblom et al. 1997; Criswell et al. 2003; Roberto et al. 2004; Izumi et al. 2005; Kash et al. 2008). However, these effects might be regionally and/or developmentally selective because other studies fail to see modulation of ethanol inhibition with these drugs (Popp et al. 1999; Criswell et al. 2003). One of the major disadvantages to these phar- macological approaches is that parallel studies for other subunits are not feasible owing to lack of sufficient pharmacological tools (GluN2A vs GluN2B) (Weitlauf et al. 2005). Additionally, the efficacy of these GluN2B-selective compounds can be modulated by zinc occupancy of the receptor, $\mathrm{pH}$, and whether the receptor contains di- versus triheteromeric subunit composition (Kash and Winder 2007; Paoletti and Neyton 2007). As will be discussed below, recent genetic deletion studies now provide additional evidence for a key role of GluN2B in NMDAR ethanol sensitivity (Wills et al. 2012).

\section{Posttranslational Effectors}

Several kinases are known to regulate the phosphorylation/dephosphorylation of NMDARs (Ron 2004). Some of these kinases show subunit-specific phosphorylation so it is likely that they can also play a role in modulating the effects of acute ethanol. Initial studies in HEK cells, however, produced either no or minimal effect of kinase activity (Src, Fyn, CaMKII) on acute ethanol sensitivity (Anders et al. 1999a,b; $\mathrm{Xu}$ et al. 2008). In contrast, later work in hippocampal neurons showed that $\mathrm{H}$-Ras activation and Src inhibition were responsible for the specific internalization of GluN2A over GluN2Bcontaining receptors via the endocytic pathway from acute ethanol (Suvarna et al. 2005). Further, acute ethanol effects on NMDAR activation could be correlated with dephosphorylation of Tyr1472 on the GluN2B subunit (Alvestad et al. 2003). This dephosphorylation of Tyr1472 on the GluN2B subunit can occur through activity of striatal-enriched protein tyrosine phosphatase (STEP). A recent study (Hicklin et al. 2011) showed that ethanol is unable to inhibit NMDAR excitatory postsynaptic currents (EPSCs) in STEP knockout (KO) mice but could be rescued with STEP TAT-fusion protein. Lack of STEP in KO mice prevented the ethanol-induced dephosphorylation of Tyr1472 on the NR2B subunit suggesting the critical nature of this site in ethanol's acute inhibitory effects. Finally, the enhancement of phosphoprotein DARPP-32 activity leads to enhanced phosphorylation of Ser-897 of the GluN1 
subunit, which in turn reduces ethanol sensitivity (Hardy et al. 1999; Maldve et al. 2002). Collectively this work indicates that the acute effects of ethanol on NMDARs has some subunit dependence; however, the particular subunit implicated varies depending on the methodological approach.

\section{CHRONIC ETHANOL EFFECTS ON NMDARs}

Although acute ethanol application has been shown to inhibit NMDAR transmission, the converse can be said for the effects of chronic ethanol applications and withdrawal. There is a general hyperexcitability of glutamate synapses and NMDARs during withdrawal from chronic ethanol (Thomas et al. 1998; Hendricson et al. 2007), which is thought to arise mainly from increased expression of NMDAR subunits after chronic ethanol administration (Follesa and Ticku 1996; Kalluri et al. 1998; Kumari 2001; Nagy et al. 2003; Pawlak et al. 2005; Sheela Rani and Ticku 2006). Further in contrast to the uncertain subunit specificity of acute ethanol effects, there are more consistent findings linking chronic ethanol administration and changes in GluN2B. Numerous studies have illustrated enhanced messenger RNA (mRNA) or expression of the GluN2B subunit either during chronic ethanol administration (Hardy et al. 1999; Henniger et al. 2003) or within the first $24 \mathrm{~h}$ of withdrawal (Follesa and Ticku 1995; Hu et al. 1996; Kalluri et al. 1998; Narita et al. 2000; Nagy et al. 2003; Hendricson et al. 2007; Qiang et al. 2007) in the hippocampus and cortex. This enhancement of GluN2B from chronic ethanol could also be mimicked by a chronic GluN2B antagonist suggesting that acute ethanol acts at GluN2B-containing receptors leading to these changes in expression (Follesa and Ticku 1996). In line with these changes in the GluN2B subunit, multiple studies find that the amount of ifenprodil-induced inhibition is also enhanced by chronic ethanol (Blevins et al. 1995; Blevins et al. 1997; Nagy et al. 2003). Therefore, this enhanced GluN2B subunit expression translates to greater functional GluN2B-containing receptors. This enhanced expression is likely related to the persistent up-regulation of GluN2B gene expression via DNA demethylation (Sheela Rani and Ticku 2006; Qiang et al. 2010). In conjunction with these changes in the GluN2B subunit, chronic ethanol also increases expression of the GluN1 subunit (Follesa and Ticku 1996; Kalluri et al. 1998; Floyd et al. 2003; Hendricson et al. 2007; Qiang et al. 2007) and in a few cases GluN2A (Follesa and Ticku 1996; Kalluri et al. 1998). The parallel changes in GluN1 and GluN2B are not surprising because the GluN1 subunit is the obligatory subunit for functional NMDARs.

In conjunction with subunit expression changes, localization of NMDARs within the synapse can also play an important role in their function. NMDARs are known to exist in both synaptic and extrasynaptic populations. The location of NMDARs with these distinct populations can differentially regulate neuronal physiology and plasticity. Extrasynaptic NMDAR populations are thought to be heavily populated by GluN2B-containing NMDARs. Chronic ethanol exposure has been reported to enhance synaptic clustering of NMDARs into dendritic spines (Carpenter-Hyland et al. 2004; Hendricson et al. 2007; Qiang et al. 2007). However, recent work has also suggested that during withdrawal there is lateral movement of GluN2Bcontaining receptors from synaptic to extrasynaptic populations in hippocampal neurons (Clapp et al. 2010). These data show there is likely a time dependence (during ethanol exposure vs. withdrawal) to the localization of GluN2B that likely has important functional consequences. Overall the effects of chronic ethanol and withdrawal lead to a general increase in NMDAR function through increases in the GluN2B subunit. It is likely that these changes in NMDAR function contribute to aberrant forms of plasticity that occur in addiction and persist during abstinence.

\section{ETHANOL EFFECTS ON PLASTICITY}

One of the primary ways that stimuli (like ethanol) can impart long-lasting changes on neural systems is through alterations in synaptic plasticity (reviewed in McCool 2011). A wide range of studies performed primarily in the 
hippocampus have shown that acute application of ethanol inhibits the induction of longterm potentiation (LTP) (Blitzer et al. 1990; Morrisett and Swartzwelder 1993; Givens 1995; Grover and Frye 1996; Schummers et al. 1997; Pyapali et al. 1999; Schummers and Browning 2001; Izumi et al. 2005; Fujii et al. 2008) and long-term depression (LTD) (Hendricson et al. 2002; Izumi et al. 2005; Jeanes et al. 2011). Meanwhile, chronic ethanol administration reduced LTP induction threshold (Fujii et al. 2008) and reduced the magnitude of LTD during withdrawal (Thinschmidt et al. 2003) in the hippocampus. Nucleus accumbens LTD was not only absent during withdrawal from chronic ethanol but instead developed into LTP (Jeanes et al. 2011). These disruptions in plasticity were attributed either fully or partially to ethanol's actions at NMDARs.

The work above illustrates a key role of ethanol in modulating the transmission of NMDARs and plasticity in a number of brain regions. More recent work has begun to evaluate the effects of ethanol in other brain areas thought to be critical for the modulation of negative affect during withdrawal (i.e., the extended amygdala). The following sections will primarily focus on a key portion of the extended amygdala, the BNST, and its importance in regulating the negative affect associated with ethanol dependence. Further, evidence will be provided to suggest that the modulation of NMDARs by ethanol is a likely mechanism for negative affect that accompanies ethanol dependence in this region.

\section{BNST CONNECTIVITY}

Evidence suggests that the BNST is a key "midde management" region, serving as an information hub upstream of key nuclei such as the VTA and the parenventricular nucleus of the hypothalamus (PVN) (Georges and Aston-Jones 2001, 2002; Jalabert et al. 2009; Ulrich-Lai and Herman 2009). The BNST is considered an integral regulator of the hypothalamic-pituitary-adrenal (HPA) stress axis (Saper and Loewy 1980; Weller and Smith 1982; Moga et al. 1989; Cullinan et al. 1993; Herman et al. 1994; McDonald et al. 1999; Dong et al. 2001a,b; Herman et al. 2002a,b, 2003; Choi et al. 2007, 2008; Ulrich-Lai and Herman 2009; Radley and Sawchenko 2011). The BNST receives "processive" or "psychogenic" stressor input from the basolateral amygdala (BLA), insular cortex, prefrontal cortex, and the hippocampal formation. The BNST also receives "systemic" stressor information (i.e., hypotension or hemorrhage) directly from ascending visceral efferent pathways. The BNST projects heavily to the PVN, the key initiator of stress responses. Control of corticotropin-releasing factor (CRF) release from the PVN (and thus ultimately levels of circulating corticosterones) is a major site of regulation of the stress response. Parvocellular CRF-containing $\mathrm{PVN}$ neurons receive synaptic input from a discrete set of brain regions and are indirectly regulated by several cortical regions and the hippocampal formation (Herman et al. 2003; Radley et al. 2009; Radley and Sawchenko 2011). Direct inputs include other hypothalamic subnuclei, brain stem nuclei such as the raphe and the nucleus of the solitary tract (NTS), and the BNST.

\section{BNST IN STRESS AND ANXIETY}

Consistent with its interconnections with the BLA and the PVN, the BNST plays a critical role in anxiety (Walker et al. 2003). IntraBNST stimulation in the awake behaving rats resulted in a behavioral phenotype very similar to the one seen during restraint stress (Casada and Dafny 1991). Restraint stress produces an increase in norepinephrine (NE) levels in the anterolateral BNST (alBNST), and microinjection of either $\beta$ - or $\alpha_{1}$-AR antagonists into the alBNST attenuates restraint stress-induced reactivity on the elevated plus maze (Cecchi et al. 2002). Curiously, $\alpha_{1}$ - but not $\beta$-AR antagonists in the BNST also disrupted stress-induced HPA axis recruitment. In addition to actions within the hypothalamus, it is now clear that CRF exerts important extrahypothalamic actions as well (Muller et al. 2003). Intracerebroventricular (ICV) CRF administration enhances fearpotentiated startle responses in rats, and this enhancement is ablated by BNST lesions (but not CeA lesions), or by microinjections of CRF antagonists into the BNST (Lee and Davis 
1997). Further, light enhancement of fear-potentiated startle is also disrupted by BNST lesions (Walker and Davis 1997). Finally, inactivation of the BNST, as well as inhibition of NE signaling in the BNST, blocks the freezing response induced by unconditioned stressors such as predator scent (Fendt et al. 2003, 2005).

\section{THE BNST PLAYS A KEY ROLE IN MEDIATING ACTIONS OF ALCOHOL}

Much evidence suggests that the BNST plays a key role in mediating aspects of alcohol abuse. First, administration of alcohol activates a relatively small number of nuclei, one of which is the alBNST (Chang et al. 1995; Demarest et al. 1998; Knapp et al. 2001; Crankshaw et al. 2003; Leriche et al. 2008; Ibba et al. 2009). Although neurons within the BNST are among a small subset of neurons to be activated by acute intraperitoneal (i.p.) ethanol administration, 45 min later this region is also one of the few to show decreased metabolic activity (Lyons et al. 1998). Withdrawal from chronic alcohol exposure is also associated with strong Fos activation in the region (Kozell et al. 2005), as is exposure to conditioned stimuli associated with ethanol (Hill et al. 2007). Evidence also suggests that rodents bred for differences in alcohol preference and intake show significant variance in expression of BDNF in restricted regions of the brain, including the BNST (Prakash et al. 2008). Moreover, manipulation of the BNST in the preferring $(\mathrm{P})$ rat strain disrupts alcohol-seeking behaviors (Eiler and June 2007), and stimulation in the $\mathrm{P}$ but not nonpreferring (NP) rat's BNST can support reward-related behavior (Eiler et al. 2007). Intraperitoneal administration of ethanol leads to increases in extracellular dopamine levels in BNST (Carboni et al. 2000), and blockade of D1 dopamine receptors (Eiler et al. 2003) or activation of $\mathrm{GABA}_{\mathrm{A}}$ Rs (Hyytia and Koob 1995) within the BNST reduces ethanol self-administration. Removal from a chronic ethanol diet results in an increase in CRF levels in BNST, which can be normalized by reexposure to ethanol (Olive et al. 2002). Finally, the BNST is one of several structures in which NMDA recruitment of c-fos activation is reduced by eth- anol (Knapp et al. 2001). Thus multiple lines of evidence suggest that alcohol regulates the activity of BNST neurons, and that this regulation is relevant to alcohol-mediated behaviors.

\section{ETHANOL ACTIONS ON NMDAR IN THE BNST}

Glutamatergic signaling in several subnuclei of the BNST is altered by acute and chronic ethanol. In the juxtacapsular (jc)BNST, protracted withdrawal from ethanol, cocaine, and heroin disrupted LTP of intrinsic excitability at glutamatergic synapses, which is characterized by reduced neuronal firing threshold and enhanced temporal firing fidelity (Francesconi et al. 2009). This effect was blocked with a $\mathrm{CRF}_{1}$ antagonist and mimicked by CRF itself indicating the dysreglulation of stress circuitry in the BNST during protracted withdrawal. In the dorsal lateral BNST (dlBNST), acute in vitro ethanol administration was able to reduce the early portion of NMDAR-dependent LTP. Additionally, acute in vitro ethanol also produced a reversible dose-dependent reduction in isolated NMDAR responses, which could be mimicked by partial NMDAR blockade (Weitlauf et al. 2004). In the ventral BNST (vBNST) using whole cell recordings, acute ethanol also inhibited NMDAR EPSCs without changing glutamate release. This inhibition by acute ethanol was still present in GluN2A knockout mouse but attenuated with a GluN2B antagonist (Kash et al. 2008). Recent work within dlBNST found that the acute inhibitory effects of ethanol were absent in a GluN2B knockout mouse and in the presence of a GluN2B antagonist. Collectively, this evidence defines the GluN2B subunit as a key determinant of acute ethanol sensitivity within the BNST (Fig. 1A,C) (Wills et al. 2012).

Similar to findings in other brain regions, chronic ethanol administration and withdrawal also enhances NMDAR transmission in the BNST. In the vBNST, chronic intermittent ethanol exposure increases NMDAR EPSC temporal summation during the early withdrawal period (Kash et al. 2009). In these chronically treated ethanol mice, there was no change in glutamate release but there were elevated GluN2B protein 
Ethanol Actions in BNST

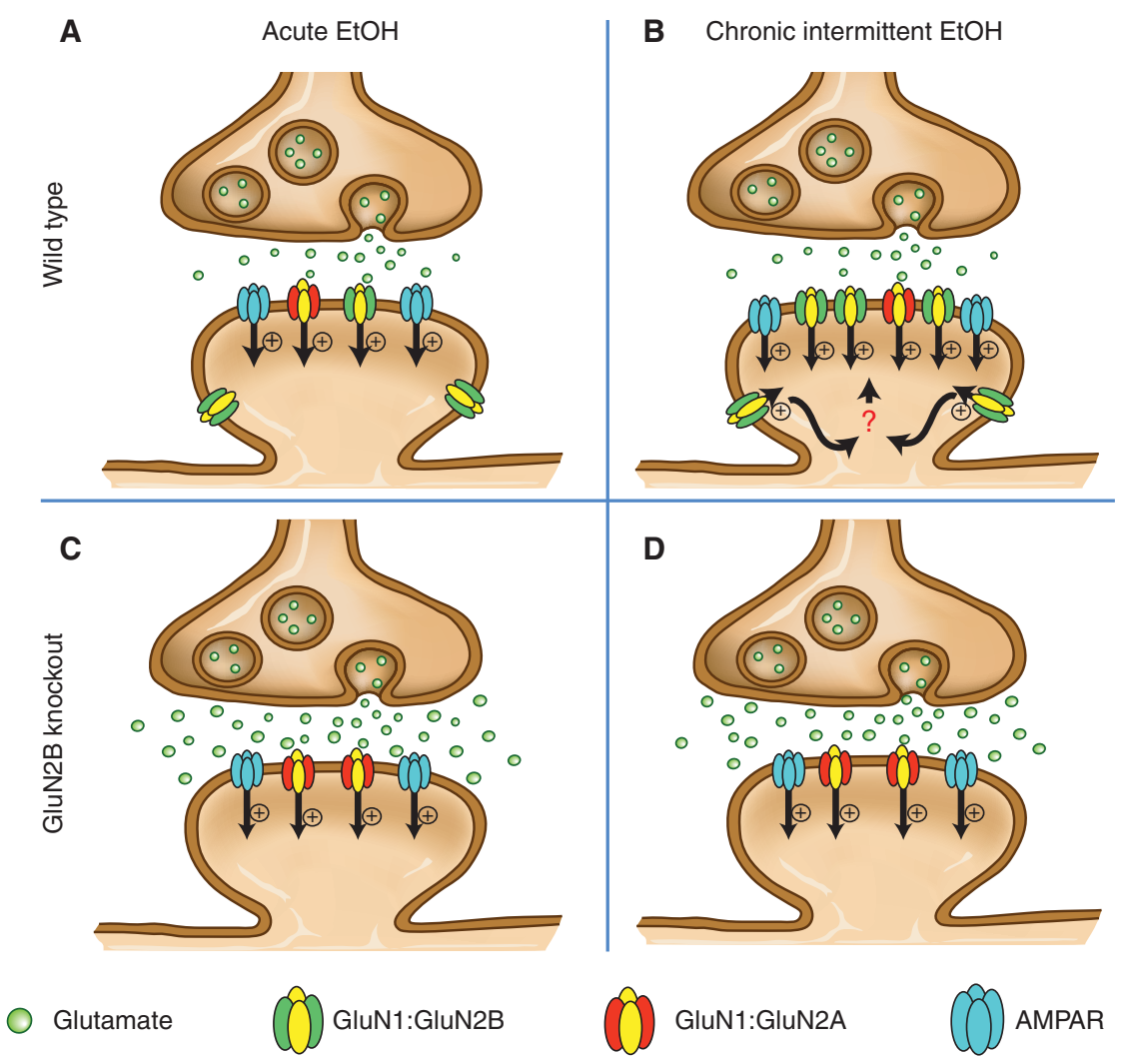

Figure 1. The acute and chronic effects of ethanol in control and GluN2B KO mice in the BNST. $(A)$ Basally, our data suggests that many BNST synapses are populated by AMPARs and NMDARs (GluN2A- and GluN2Bcontaining). During acute ethanol application to the slice, there is an inhibition of glutamate transmission. Our work has shown that this is specific to the NMDARs that are GluN2B-containing because no ethanol inhibition occurs in slices from GluN2B KO mice $(B)$. $(C)$ Following chronic intermittent ethanol, we find enhancement of long-term potentiation (LTP) that is GluN2B dependent because this effect is absent in GluN2B KO mice $(D)$. We postulate that this LTP enhancement results from increased synaptic GluN2B-containing receptors. Further, our data illustrate that extrasynaptic GluN2B-containing receptors contribute to synaptic signaling (although the mechanism is unknown) to enhance LTP after chronic intermittent ethanol.

levels and increased GluN2B antagonism on NMDAR EPSCs and decay kinetics (Kash et al. 2009). These changes are consistent with functional up-regulation of GluN2B from chronic ethanol and it is this increase that likely contributes to enhanced temporal summation of NMDAR EPSCs. Later work in the dIBNST also suggested an enhancement of GluN2Bdependent transmission. Chronic intermittent ethanol exposure enhanced LTP during early withdrawal compared to air-exposed controls. This ethanol-induced enhancement was absent in the GluN2B knockout mice lending further support to the role of GluN2B in adaptations from chronic ethanol (Fig. 1B,D) (Wills et al. 2012). Additionally, chronic ethanol exposure blunted the inhibitory effects of acute in vitro ethanol administration in the vBNST suggesting that NMDARs likely develop tolerance to the acute ethanol effects (Kash et al. 2009). This is particularly curious given the key role of GluN2B in ethanol sensitivity of NMDARs in this region coupled with its increased expression after chronic exposure. Again, this discrepancy likely points to the importance of posttranslational modifications of NMDARs in control of 
ethanol sensitivity. In total, this work in the BNST shows that, similar to other brain regions, acute ethanol has an inhibitory role on glutamatergic signaling, whereas chronic ethanol treatment enhances its function. Subsequently, with the combined approach of both pharmacological modulation and genetic deletion, these ethanol effects have been shown to be GluN2B dependent.

As described above, both subunit selectivity and synaptic localization are critical factors in determining the net effect of ethanol on glutamatergic transmission and plasticity. In other brain regions chronic ethanol leads to increased synaptic clustering of NMDARs and during withdrawal GluN2B-containing NMDARs move to extrasynaptic populations (Carpenter-Hyland et al. 2004; Hendricson et al. 2007; Qiang et al. 2007; Clapp et al. 2010). Our recent work (Wills et al. 2012) in the dlBNST supports this idea of enhanced extrasynaptic GluN2B populations and illuminates how their function can contribute to plasticity. This work took advantage of the unique pharmacology of ifenprodil and ifenprodil derivatives (GluN2B antagonist). These drugs have the dual role of noncompetitive inhibition of GluN2B-containing NMDARs and enhancing glutamate affinity. We found that low doses of an ifenprodil derivative, Ro25-6981, could enhance GluN2B-dependent NMDA transmission likely through its glutamate affinity enhancing effects on extrasynaptic NMDAR populations. During acute withdrawal from chronic intermittent ethanol, it was shown that this low dose of Ro25-6981 enhanced LTP only in ethanol-treated mice. This enhanced LTP could be blocked with lowdose memantine, which preferentially inhibits extrasynaptic NMDARs at low doses. Collectively, this work provides additional support for the enhancement of extrasynaptic GluN2B-containing NMDARs during withdrawal (Fig. 1B). Moreover, this population functions to enhance LTP in this region. This idea is in contrast with conventional thought regarding the role of extrasynaptic GluN2B-containing NMDARs in promoting LTD over LTP in other brain areas (Liu et al. 2004; Massey et al. 2004). Thus, these results suggest either regional differences in extrasynaptic GluN2B signaling or ethanol-induced changes in the normal intracellular cascades of this population.

\section{ETHANOL ACTIONS ON NMDARs IN THE BASOLATERAL AND CENTRAL AMYGDALA}

NMDARs in the BLA and CeA also play important roles in negative affect and are heavily interconnected to the BNST. NMDAR LTP can be elicited at glutamate synapses in each of these brain regions (Pollandt et al. 2006). Further, acute applications of ethanol dose dependently inhibit NMDAR in the BLA and CeA (Floyd et al. 2003; Roberto et al. 2004). This acute ethanol inhibition was removed by preapplication of the GluN2B-selective antagonist in the CeA (Roberto et al. 2004), similar to the results in the BNST (Kash et al. 2008). After chronic ethanol exposure, an enhanced ethanol sensitivity of NMDAR EPSCs was observed, which was sensitive to GluN2B antagonism and associated with increased GluN2B expression (Roberto et al. 2004). In the basolateral nucleus of the amygdala, chronic ethanol treatment increased NMDAR current density, did not change acute ethanol sensitivity, and enhanced ifenprodil inhibition (Floyd et al. 2003). However, this treatment did not result in altered GluN2B mRNA levels (Floyd et al. 2003). Evidence from this work further supports that these actions of ethanol on the NMDAR are GluN2B dependent. However, regional differences in ethanol sensitivity could suggest that posttranslational modifications of NMDARs might be distinct in different brain regions. Further, it is currently unknown how synaptic and extrasynaptic populations might be affected in these regions following chronic ethanol.

\section{CONCLUDING REMARK}

In summary, a large body of data indicates that the NMDAR is a major target of ethanol in the BNST. Both acutely and chronically, the GluN2B subunit of the NMDAR plays a critical role in this sensitivity. As this receptor plays a critical role in the long-term setting of synaptic 
weights, dysregulation of the receptor may reset key neural circuitries within the extended amygdala, thus increasing the drive for negative-reinforcement-based behavior. As the NMDAR plays a major role at synapses throughout the CNS, it seems unlikely that typical competitive antagonists will be an effective strategy in the treatment of addiction. However, the recognition of subunit dependence to ethanol sensitivity, coupled with an evolving variety of allosteric and use-dependent antagonists may lead to more subtle means of addressing ethanol sensitivity of these receptors.

\section{ACKNOWLEDGMENT}

We thank Katie Louderback for artwork.

\section{REFERENCES}

Alvestad RM, Grosshans DR, Coultrap SJ, Nakazawa T, Yamamoto T, Browning MD. 2003. Tyrosine dephosphorylation and ethanol inhibition of $N$-methyl-D-aspartate receptor function. J Biol Chem 278: 1102011025.

Anders DL, Blevins T, Sutton G, Chandler LJ, Woodward JJ. 1999a. Effects of c-Src tyrosine kinase on ethanol sensitivity of recombinant NMDA receptors expressed in HEK 293 cells. Alcohol Clin Exp Res 23: 357-362.

Anders DL, Blevins T, Sutton G, Swope S, Chandler LJ, Woodward JJ. 1999b. Fyn tyrosine kinase reduces the ethanol inhibition of recombinant NR1/NR2A but not NR1/NR2B NMDA receptors expressed in HEK 293 cells. J Neurochem 72: 1389-1393.

Anders DL, Blevins T, Smothers CT, Woodward JJ. 2000. Reduced ethanol inhibition of $N$-methyl-D-aspartate receptors by deletion of the NR1 C0 domain or overexpression of $\alpha$-actinin-2 proteins. J Biol Chem 275: 1501915024.

Begleiter H, Porjesz B. 1979. Persistence of a "subacute withdrawal syndrome" following chronic ethanol intake. Drug Alcohol Depend 4: 353-357.

Blevins T, Mirshahi T, Woodward JJ. 1995. Increased agonist and antagonist sensitivity of $N$-methyl-D-aspartate stimulated calcium flux in cultured neurons following chronic ethanol exposure. Neurosci Lett 200: 214-218.

Blevins T, Mirshahi T, Chandler LJ, Woodward JJ. 1997. Effects of acute and chronic ethanol exposure on heteromeric $N$-methyl-D-aspartate receptors expressed in HEK 293 cells. J Neurochem 69: 2345-2354.

Blitzer RD, Gil O, Landau EM. 1990. Long-term potentiation in rat hippocampus is inhibited by low concentrations of ethanol. Brain Res 537: 203-208.

Carboni E, Silvagni A, Rolando MT, Di Chiara G. 2000. Stimulation of in vivo dopamine transmission in the bed nucleus of stria terminalis by reinforcing drugs. $J$ Neurosci 20: RC102.

Carpenter-Hyland EP, Woodward JJ, Chandler LJ. 2004. Chronic ethanol induces synaptic but not extrasynaptic targeting of NMDA receptors. J Neurosci 24: 7859-7868.

Casada JH, Dafny N. 1991. Restraint and stimulation of bed nucleus of the stria terminalis produce similar stress-like behaviors. Brain Res Bull 27: 207-212.

Cecchi M, Khoshbouei H, Javors M, Morilak DA. 2002. Modulatory effects of norepinephrine in the lateral bed nucleus of the stria terminalis on behavioral and neuroendocrine responses to acute stress. Neuroscience 112: 13-21.

Chang SL, Patel NA, Romero AA. 1995. Activation and desensitization of Fos immunoreactivity in the rat brain following ethanol administration. Brain Res 679: 89-98.

Choi DC, Furay AR, Evanson NK, Ostrander MM, UlrichLai YM, Herman JP. 2007. Bed nucleus of the stria terminalis subregions differentially regulate hypothalamic-pituitary-adrenal axis activity: Implications for the integration of limbic inputs. J Neurosci 27: 2025-2034.

Choi DC, Evanson NK, Furay AR, Ulrich-Lai YM, Ostrander MM, Herman JP. 2008. The anteroventral bed nucleus of the stria terminalis differentially regulates hypothalamic-pituitary-adrenocortical axis responses to acute and chronic stress. Endocrinology 149: 818-826.

Chu B, Anantharam V, Treistman SN. 1995. Ethanol inhibition of recombinant heteromeric NMDA channels in the presence and absence of modulators. J Neurochem 65: 140-148.

Clapp P, Gibson ES, Dell'acqua ML, Hoffman PL. 2010. Phosphorylation regulates removal of synaptic $N$-methyl-D-aspartate receptors after withdrawal from chronic ethanol exposure. J Pharmacol Exp Ther 332: 720-729.

Crankshaw DL, Briggs JE, Olszewski PK, Shi Q, Grace MK, Billington CJ, Levine AS. 2003. Effects of intracerebroventricular ethanol on ingestive behavior and induction of c-Fos immunoreactivity in selected brain regions. Physiol Behav 79: 113-120.

Criswell HE, Ming Z, Griffith BL, Breese GR. 2003. Comparison of effect of ethanol on $N$-methyl-D-aspartateand GABA-gated currents from acutely dissociated neurons: Absence of regional differences in sensitivity to ethanol. J Pharmacol Exp Ther 304: 192-199.

Cull-Candy S, Brickley S, Farrant M. 2001. NMDA receptor subunits: Diversity, development and disease. Curr Opin Neurobiol 11: 327-335.

Cullinan WE, Herman JP, Watson SJ. 1993. Ventral subicular interaction with the hypothalamic paraventricular nucleus: Evidence for a relay in the bed nucleus of the stria terminalis. J Comp Neurol 332: 1-20.

de Marchena J, Roberts AC, Middlebrooks PG, Valakh V, Yashiro K, Wilfley LR, Philpot BD. 2008. NMDA receptor antagonists reveal age-dependent differences in the properties of visual cortical plasticity. J Neurophysiol 100: 1936-1948.

Demarest K, Hitzemann B, Mahjubi E, McCaughran J Jr, Hitzemann R. 1998. Further evidence that the central nucleus of the amygdala is associated with the ethanolinduced locomotor response. Alcohol Clin Exp Res 22: 1531-1537. 
T.A. Wills and D.G. Winder

De Soto CB, O’Donnell WE, Allred LJ, Lopes CE. 1985 Symptomatology in alcoholics at various stages of abstinence. Alcohol Clin Exp Res 9: 505-512.

Dildy JE, Leslie SW. 1989. Ethanol inhibits NMDA-induced increases in free intracellular $\mathrm{Ca}^{2+}$ in dissociated brain cells. Brain Res 499: 383-387.

Dong HW, Petrovich GD, Swanson LW. 2001a. Topography of projections from amygdala to bed nuclei of the stria terminalis. Brain Res Brain Res Rev 38: 192-246.

Dong HW, Petrovich GD, Watts AG, Swanson LW. 2001b. Basic organization of projections from the oval and fusiform nuclei of the bed nuclei of the stria terminalis in adult rat brain. J Comp Neurol 436: 430-455.

Eiler WJ 2nd, June HL. 2007. Blockade of $\mathrm{GABA}_{\mathrm{A}}$ receptors within the extended amygdala attenuates $\mathrm{D}_{2}$ regulation of alcohol-motivated behaviors in the ventral tegmental area of alcohol-preferring (P) rats. Neuropharmacology 52: $1570-1579$.

Eiler WJ 2nd, Seyoum R, Foster KL, Mailey C, June HL. 2003. D1 dopamine receptor regulates alcohol-motivated behaviors in the bed nucleus of the stria terminalis in alcohol-preferring (P) rats. Synapse 48: 45-56.

Eiler WJ 2nd, Hardy L 3rd, Goergen J, Seyoum R, MensahZoe B, June HL. 2007. Responding for brain stimulation reward in the bed nucleus of the stria terminalis in alcohol-preferring rats following alcohol and amphetamine pretreatments. Synapse 61: 912-924.

Engblom AC, Courtney MJ, Kukkonen JP, Akerman KE. 1997. Ethanol specifically inhibits NMDA receptors with affinity for ifenprodil in the low micromolar range in cultured cerebellar granule cells. J Neurochem 69: 2162-2168.

Fendt M, Endres T, Apfelbach R. 2003. Temporary inactivation of the bed nucleus of the stria terminalis but not of the amygdala blocks freezing induced by trimethylthiazoline, a component of fox feces. J Neurosci 23: 23-28.

Fendt M, Siegl S, Steiniger-Brach B. 2005. Noradrenaline transmission within the ventral bed nucleus of the stria terminalis is critical for fear behavior induced by trimethylthiazoline, a component of fox odor. J Neurosci 25: 5998-6004.

Fink K, Gothert M. 1996. Both ethanol and ifenprodil inhibit NMDA-evoked release of various neurotransmitters at different, yet proportional potency: Potential relation to NMDA receptor subunit composition. Naunyn Schmiedebergs Arch Pharmacol 354: 312-319.

Floyd DW, Jung KY, McCool BA. 2003. Chronic ethanol ingestion facilitates $\mathrm{N}$-methyl-D-aspartate receptor function and expression in rat lateral/basolateral amygdala neurons. J Pharmacol Exp Ther 307: 1020-1029.

Follesa P, Ticku MK. 1995. Chronic ethanol treatment differentially regulates NMDA receptor subunit mRNA expression in rat brain. Brain Res Mol Brain Res 29: 99-106.

Follesa P, Ticku MK. 1996. NMDA receptor upregulation: Molecular studies in cultured mouse cortical neurons after chronic antagonist exposure. J Neurosci 16: $2172-$ 2178.

Francesconi W, Berton F, Repunte-Canonigo V, Hagihara K, Thurbon D, Lekic D, Specio SE, Greenwell TN, Chen SA, Rice KC, et al. 2009. Protracted withdrawal from alcohol and drugs of abuse impairs long-term potentiation of intrinsic excitability in the juxtacapsular bed nucleus of the stria terminalis. J Neurosci 29: 5389-5401.

Fujii S, Yamazaki Y, Sugihara T, Wakabayashi I. 2008. Acute and chronic ethanol exposure differentially affect induction of hippocampal LTP. Brain Res 1211: 13-21.

Georges F, Aston-Jones G. 2001. Potent regulation of midbrain dopamine neurons by the bed nucleus of the stria terminalis. J Neurosci 21: RC160.

Georges F, Aston-Jones G. 2002. Activation of ventral tegmental area cells by the bed nucleus of the stria terminalis: A novel excitatory amino acid input to midbrain dopamine neurons. J Neurosci 22: 5173-5187.

Givens B. 1995. Low doses of ethanol impair spatial working memory and reduce hippocampal $\theta$ activity. Alcohol Clin Exp Res 19: 763-767.

Givens B, McMahon K. 1995. Ethanol suppresses the induction of long-term potentiation in vivo. Brain Res 688: $27-33$.

Grant I, Reed R, Adams KM. 1987. Diagnosis of intermediate-duration and subacute organic mental disorders in abstinent alcoholics. J Clin Psychiatry 48: 319-323.

Grover CA, Frye GD. 1996. Ethanol effects on synaptic neurotransmission and tetanus-induced synaptic plasticity in hippocampal slices of chronic in vivo lead-exposed adult rats. Brain Res 734: 61-71.

Hardy PA, Chen W, Wilce PA. 1999. Chronic ethanol exposure and withdrawal influence NMDA receptor subunit and splice variant mRNA expression in the rat cerebral cortex. Brain Res 819: 33-39.

Hendricson AW, Miao CL, Lippmann MJ, Morrisett RA. 2002. Ifenprodil and ethanol enhance NMDA receptordependent long-term depression. J Pharmacol Exp Ther 301: 938-944.

Hendricson AW, Maldve RE, Salinas AG, Theile JW, Zhang TA, Diaz LM, Morrisett RA. 2007. Aberrant synaptic activation of $N$-methyl-D-aspartate receptors underlies ethanol withdrawal hyperexcitability. J Pharmacol Exp Ther 321: 60-72.

Henniger MS, Wotjak CT, Holter SM. 2003. Long-term voluntary ethanol drinking increases expression of NMDA receptor 2B subunits in rat frontal cortex. Eur J Pharmacol 470: 33-36.

Herman JP, Cullinan WE, Watson SJ. 1994. Involvement of the bed nucleus of the stria terminalis in tonic regulation of paraventricular hypothalamic CRH and AVP mRNA expression. J Neuroendocrinol 6: 433-442.

Herman JP, Cullinan WE, Ziegler DR, Tasker JG. 2002a. Role of the paraventricular nucleus microenvironment in stress integration. Eur J Neurosci 16: 381-385.

Herman JP, Tasker JG, Ziegler DR, Cullinan WE. 2002b. Local circuit regulation of paraventricular nucleus stress integration: Glutamate-GABA connections. Pharmacol Biochem Behav 71: 457-468.

Herman JP, Figueiredo H, Mueller NK, Ulrich-Lai Y, Ostrander MM, Choi DC, Cullinan WE. 2003. Central mechanisms of stress integration: Hierarchical circuitry controlling hypothalamo-pituitary-adrenocortical responsiveness. Front Neuroendocrinol 24: 151-180.

Hershon H. 1977. Learning to be an alcoholic. J Psychosom Res 21: 297-306. 
Hicklin TR, Wu PH, Radcliffe RA, Freund RK, GoebelGoody SM, Correa PR, Proctor WR, Lombroso PJ, Browning MD. 2011. Alcohol inhibition of the NMDA receptor function, long-term potentiation, and fear learning requires striatal-enriched protein tyrosine phosphatase. Proc Natl Acad Sci 108: 6650-6655.

Hill KG, Ryabinin AE, Cunningham CL. 2007. FOS expression induced by an ethanol-paired conditioned stimulus. Pharmacol Biochem Behav 87: 208-221.

Hoffman PL, Rabe CS, Moses F, Tabakoff B. 1989. N-methylD-aspartate receptors and ethanol: Inhibition of calcium flux and cyclic GMP production. J Neurochem 52: 1937-1940.

Honse Y, Ren H, Lipsky RH, Peoples RW. 2004. Sites in the fourth membrane-associated domain regulate alcohol sensitivity of the NMDA receptor. Neuropharmacology 46: 647-654.

Hu XJ, Follesa P, Ticku MK. 1996. Chronic ethanol treatment produces a selective upregulation of the NMDA receptor subunit gene expression in mammalian cultured cortical neurons. Brain Res Mol Brain Res 36: 211-218.

Hyytia P, Koob GF. 1995. GABA receptor antagonism in the extended amygdala decreases ethanol self-administration in rats. Eur J Pharmacol 283: 151-159.

Ibba F, Vinci S, Spiga S, Peana AT, Assaretti AR, Spina L, Longoni R, Acquas E. 2009. Ethanol-induced extracellular signal regulated kinase: Role of dopamine D1 receptors. Alcohol Clin Exp Res 33: 858-867.

Izumi Y, Nagashima K, Murayama K, Zorumski CF. 2005. Acute effects of ethanol on hippocampal long-term potentiation and long-term depression are mediated by different mechanisms. Neuroscience 136: 509-517.

Jalabert M, Aston-Jones G, Herzog E, Manzoni O, Georges F. 2009. Role of the bed nucleus of the stria terminalis in the control of ventral tegmental area dopamine neurons. Prog Neuropsychopharmacol Biol Psychiatry 33: 13361346.

Jeanes ZM, Buske TR, Morrisett RA. 2011. In vivo chronic intermittent ethanol exposure reverses the polarity of synaptic plasticity in the nucleus accumbens shell. J Pharmacol Exp Ther 336: 155-164.

Jin C, Woodward JJ. 2006. Effects of 8 different NR1 splice variants on the ethanol inhibition of recombinant NMDA receptors. Alcohol Clin Exp Res 30: 673-679.

Kalluri HS, Mehta AK, Ticku MK. 1998. Up-regulation of NMDA receptor subunits in rat brain following chronic ethanol treatment. Brain Res Mol Brain Res 58: 221-224.

Kash T, Winder D. 2007. NMDAR LTP and LTD induction: $2 \mathrm{~B}$ or not $2 \mathrm{~B} \ldots$ is that the question? Debates Neurosci 1: 79-84.

Kash TL, Matthews RT, Winder DG. 2008. Alcohol inhibits NR2B-containing NMDA receptors in the ventral bed nucleus of the stria terminalis. Neuropsychopharmacology 33: $1379-1390$.

Kash TL, Baucum AJ 2nd, Conrad KL, Colbran RJ, Winder DG. 2009. Alcohol exposure alters NMDAR function in the bed nucleus of the stria terminalis. Neuropsychopharmacology 34: 2420-2429.

Knapp DJ, Braun CJ, Duncan GE, Qian Y, Fernandes A, Crews FT, Breese GR. 2001. Regional specificity of ethanol and NMDA action in brain revealed with FOS-like im- munohistochemistry and differential routes of drug administration. Alcohol Clin Exp Res 25: 1662-1672.

Koob GF, Le Moal M. 1997. Drug abuse: Hedonic homeostatic dysregulation. Science 278: 52-58.

Kozell LB, Hitzemann R, Buck KJ. 2005. Acute alcohol withdrawal is associated with c-Fos expression in the basal ganglia and associated circuitry: C57BL/6J and DBA/2J inbred mouse strain analyses. Alcohol Clin Exp Res 29: 1939-1948.

Kumari M. 2001. Differential effects of chronic ethanol treatment on $N$-methyl-D-aspartate R1 splice variants in fetal cortical neurons. J Biol Chem 276: 29764-29771.

Kuner T, Schoepfer R, Korpi ER. 1993. Ethanol inhibits glutamate-induced currents in heteromeric NMDA receptor subtypes. Neuroreport 5: 297-300.

Le AD, Harding S, Juzytsch W, Watchus J, Shalev U, Shaham Y. 2000. The role of corticotrophin-releasing factor in stress-induced relapse to alcohol-seeking behavior in rats. Psychopharmacology 150: 317-324.

Lee Y, Davis M. 1997. Role of the hippocampus, the bed nucleus of the stria terminalis, and the amygdala in the excitatory effect of corticotropin-releasing hormone on the acoustic startle reflex. J Neurosci 17: 6434-6446.

Leriche M, Mendez M, Zimmer L, Berod A. 2008. Acute ethanol induces Fos in GABAergic and non-GABAergic forebrain neurons: A double-labeling study in the medial prefrontal cortex and extended amygdala. Neuroscience 153: $259-267$.

Liu L, Wong TP, Pozza MF, Lingenhoehl K, Wang Y, Sheng M, Auberson YP, Wang YT. 2004. Role of NMDA receptor subtypes in governing the direction of hippocampal synaptic plasticity. Science 304: 1021-1024.

Lovinger DM. 1995. Developmental decrease in ethanol inhibition of $N$-methyl-D-aspartate receptors in rat neocortical neurons: Relation to the actions of ifenprodil. J Pharmacol Exp Ther 274: 164-172.

Lovinger DM, White G, Weight FF. 1989. Ethanol inhibits NMDA-activated ion current in hippocampal neurons. Science 243: 1721-1724.

Lyons D, Whitlow CT, Porrino LJ. 1998. Multiphasic consequences of the acute administration of ethanol on cerebral glucose metabolism in the rat. Pharmacol Biochem Behav 61: 201-206.

Maldve RE, Zhang TA, Ferrani-Kile K, Schreiber SS, Lippmann MJ, Snyder GL, Fienberg AA, Leslie SW, Gonzales RA, Morrisett RA. 2002. DARPP-32 and regulation of the ethanol sensitivity of NMDA receptors in the nucleus accumbens. Nat Neurosci 5: 641-648.

Masood K, Wu C, Brauneis U, Weight FF. 1994. Differential ethanol sensitivity of recombinant $N$-methyl-D-aspartate receptor subunits. Mol Pharmacol 45: 324-329.

Massey PV, Johnson BE, Moult PR, Auberson YP, Brown MW, Molnar E, Collingridge GL, Bashir ZI. 2004. Differential roles of NR2A and NR2B-containing NMDA receptors in cortical long-term potentiation and long-term depression. J Neurosci 24: 7821-7828.

McCool BA. 2011. Ethanol modulation of synaptic plasticity. Neuropharmacology 61: 1097-1108.

McDonald AJ, Shammah-Lagnado SJ, Shi C, Davis M. 1999. Cortical afferents to the extended amygdala. Ann NYAcad Sci 877: 309-338. 
T.A. Wills and D.G. Winder

Mirshahi T, Woodward JJ. 1995. Ethanol sensitivity of heteromeric NMDA receptors: Effects of subunit assembly, glycine and NMDAR1 $\mathrm{Mg}^{2+}$-insensitive mutants. Neuropharmacology 34: 347-355.

Mirshahi T, Anders DL, Ronald KM, Woodward JJ. 1998. Intracellular calcium enhances the ethanol sensitivity of NMDA receptors through an interaction with the C0 domain of the NR1 subunit. J Neurochem 71: 1095-1107.

Moga MM, Saper CB, Gray TS. 1989. Bed nucleus of the stria terminalis: Cytoarchitecture, immunohistochemistry, and projection to the parabrachial nucleus in the rat. J Comp Neurol 283: 315-332.

Morrisett RA, Swartzwelder HS. 1993. Attenuation of hippocampal long-term potentiation by ethanol: A patchclamp analysis of glutamatergic and GABAergic mechanisms. J Neurosci 13: 2264-2272.

Muller MB, Zimmermann S, Sillaber I, Hagemeyer TP, Deussing JM, Timpl P, Kormann MS, Droste SK, Kuhn R, Reul JM, et al. 2003. Limbic corticotropin-releasing hormone receptor 1 mediates anxiety-related behavior and hormonal adaptation to stress. Nat Neurosci 6: 1100-1107.

Nagy J, Kolok S, Dezso P, Boros A, Szombathelyi Z. 2003. Differential alterations in the expression of NMDA receptor subunits following chronic ethanol treatment in primary cultures of rat cortical and hippocampal neurones. Neurochem Int 42: 35-43.

Narita M, Soma M, Mizoguchi H, Tseng LF, Suzuki T. 2000. Implications of the NR2B subunit-containing NMDA receptor localized in mouse limbic forebrain in ethanol dependence. Eur J Pharmacol 401: 191-195.

Olive MF, Koenig HN, Nannini MA, Hodge CW. 2002. Elevated extracellular CRF levels in the bed nucleus of the stria terminalis during ethanol withdrawal and reduction by subsequent ethanol intake. Pharmacol Biochem Behav 72: 213-220.

Paoletti P, Neyton J. 2007. NMDA receptor subunits: Function and pharmacology. Curr Opin Pharmacol 7: 39-47.

Pawlak R, Melchor JP, Matys T, Skrzypiec AE, Strickland S. 2005. Ethanol-withdrawal seizures are controlled by tissue plasminogen activator via modulation of NR2B-containing NMDA receptors. Proc Natl Acad Sci 102: 443 448.

Pollandt S, Liu J, Orozco-Cabal L, Grigoriadis DE, Vale WW, Gallagher JP, Shinnick-Gallagher P. 2006. Cocaine withdrawal enhances long-term potentiation induced by corticotropin-releasing factor at central amygdala glutamatergic synapses via CRF, NMDA receptors and PKA. Eur J Neurosci 24: 1733-1743.

Popp RL, Lickteig R, Browning MD, Lovinger DM. 1998. Ethanol sensitivity and subunit composition of NMDA receptors in cultured striatal neurons. Neuropharmacology 37: 45-56.

Popp RL, Lickteig RL, Lovinger DM. 1999. Factors that enhance ethanol inhibition of $N$-methyl-D-aspartate receptors in cerebellar granule cells. J Pharmacol Exp Ther 289: 1564-1574

Prakash A, Zhang H, Pandey SC. 2008. Innate differences in the expression of brain-derived neurotrophic factor in the regions within the extended amygdala between alcohol preferring and nonpreferring rats. Alcohol Clin Exp Res 32: 909-920.
Pyapali GK, Turner DA, Wilson WA, Swartzwelder HS. 1999. Age and dose-dependent effects of ethanol on the induction of hippocampal long-term potentiation. Alcohol 19: 107-111.

Qiang M, Denny AD, Ticku MK. 2007. Chronic intermittent ethanol treatment selectively alters $N$-methyl-D-aspartate receptor subunit surface expression in cultured cortical neurons. Mol Pharmacol 72: 95-102.

Qiang M, Denny A, Chen J, Ticku MK, Yan B, Henderson G. 2010. The site specific demethylation in the $5^{\prime}$-regulatory area of NMDA receptor 2B subunit gene associated with CIE-induced up-regulation of transcription. PloS ONE 5: e8798.

Radley JJ, Sawchenko PE. 2011. A common substrate for prefrontal and hippocampal inhibition of the neuroendocrine stress response. J Neurosci 31: 9683-9695.

Radley JJ, Gosselink KL, Sawchenko PE. 2009. A discrete GABAergic relay mediates medial prefrontal cortical inhibition of the neuroendocrine stress response. J Neurosci 29: $7330-7340$.

Ren H, Honse Y, Peoples RW. 2003. A site of alcohol action in the fourth membrane-associated domain of the $N$-methyl-D-aspartate receptor. J Biol Chem 278: 48815-48820.

Ren H, Salous AK, Paul JM, Lipsky RH, Peoples RW. 2007. Mutations at F637 in the NMDA receptor NR2A subunit M3 domain influence agonist potency, ion channel gating and alcohol action. Br J Pharmacol 151: 749-757.

Roberto M, Schweitzer P, Madamba SG, Stouffer DG, Parsons LH, Siggins GR. 2004. Acute and chronic ethanol alter glutamatergic transmission in rat central amygdala: An in vitro and in vivo analysis. J Neurosci 24: 1594-1603.

Roelofs SM. 1985. Hyperventilation, anxiety, craving for alcohol: A subacute alcohol withdrawal syndrome. Alcohol 2: 501-505.

Ron D. 2004. Signaling cascades regulating NMDA receptor sensitivity to ethanol. Neuroscientist 10: 325-336.

Ronald KM, Mirshahi T, Woodward JJ. 2001. Ethanol inhibition of $\mathrm{N}$-methyl-D-aspartate receptors is reduced by site-directed mutagenesis of a transmembrane domain phenylalanine residue. J Biol Chem 276: 44729-44735.

Saper CB, Loewy AD. 1980. Efferent connections of the parabrachial nucleus in the rat. Brain Res 197: 291-317.

Schummers J, Browning MD. 2001. Evidence for a role for $\mathrm{GABA}_{\mathrm{A}}$ and NMDA receptors in ethanol inhibition of long-term potentiation. Brain Res Mol Brain Res 94: 9-14.

Schummers J, Bentz S, Browning MD. 1997. Ethanol's inhibition of LTP may not be mediated solely via direct effects on the NMDA receptor. Alcohol Clin Exp Res 21: 404-408.

Sheela Rani CS, Ticku MK. 2006. Comparison of chronic ethanol and chronic intermittent ethanol treatments on the expression of $\mathrm{GABA}_{\mathrm{A}}$ and NMDA receptor subunits. Alcohol 38: 89-97.

Sinha R. 2001. How does stress increase risk of drug abuse and relapse? Psychopharmacology 158: 343-359.

Smothers CT, Woodward JJ. 2006. Effects of amino acid substitutions in transmembrane domains of the NR1 subunit on the ethanol inhibition of recombinant $N$ - 
methyl-D-aspartate receptors. Alcohol Clin Exp Res 30: 523-530.

Smothers CT, Clayton R, Blevins T, Woodward JJ. 2001. Ethanol sensitivity of recombinant human $N$-methyl-Daspartate receptors. Neurochem Int 38: 333-340.

Suvarna N, Borgland SL, Wang J, Phamluong K, Auberson YP, Bonci A, Ron D. 2005. Ethanol alters trafficking and functional $\mathrm{N}$-methyl-D-aspartate receptor NR2 subunit ratio via H-Ras. J Biol Chem 280: 31450-31459.

Thinschmidt JS, Walker DW, King MA. 2003. Chronic ethanol treatment reduces the magnitude of hippocampal LTD in the adult rat. Synapse 48: 189-197.

Thomas MP, Monaghan DT, Morrisett RA. 1998. Evidence for a causative role of $N$-methyl-D-aspartate receptors in an in vitro model of alcohol withdrawal hyperexcitability. J Pharmacol Exp Ther 287: 87-97.

Traynelis SF, Wollmuth LP, McBain CJ, Menniti FS, Vance KM, Ogden KK, Hansen KB, Yuan H, Myers SJ, Dingledine R. 2010. Glutamate receptor ion channels: Structure, regulation, and function. Pharmacol Rev 62: 405-496.

Ulrich-Lai YM, Herman JP. 2009. Neural regulation of endocrine and autonomic stress responses. Nat Rev Neurosci 10: 397-409.

Walker DL, Davis M. 1997. Double dissociation between the involvement of the bed nucleus of the stria terminalis and the central nucleus of the amygdala in startle increases produced by conditioned versus unconditioned fear. Neurosci 17: 9375-9383.
Walker DL, Toufexis DJ, Davis M. 2003. Role of the bed nucleus of the stria terminalis versus the amygdala in fear, stress, and anxiety. Eur J Pharmacol 463: 199-216.

Weitlauf C, Egli RE, Grueter BA, Winder DG. 2004. Highfrequency stimulation induces ethanol-sensitive longterm potentiation at glutamatergic synapses in the dorsolateral bed nucleus of the stria terminalis. J Neurosci 24: 5741-5747.

Weitlauf C, Honse Y, Auberson YP, Mishina M, Lovinger DM, Winder DG. 2005. Activation of NR2A-containing NMDA receptors is not obligatory for NMDA receptor-dependent long-term potentiation. J Neurosci 25: 8386-8390.

Weller KL, Smith DA. 1982. Afferent connections to the bed nucleus of the stria terminalis. Brain Res 232: 255-270.

Wills T, Klug J, Silberman Y, Baucum A, Weitlauf C, Colbran R, Delpire E, Winder D. 2012. GluN2B subunit deletion reveals key role in acute and chronic ethanol sensitivity of glutamate synapses in bed nucleus of the stria terminalis. Proc Natl Acad Sci 109: E278E287.

Xu M, Chandler LJ, Woodward JJ. 2008. Ethanol inhibition of recombinant NMDA receptors is not altered by coexpression of CaMKII- $\alpha$ or CaMKII- $\beta$. Alcohol 42: 425432.

Xu M, Smothers CT, Woodward JJ. 2011. Effects of ethanol on phosphorylation site mutants of recombinant $N$ methyl-D-aspartate receptors. Alcohol 45: 373-380. 


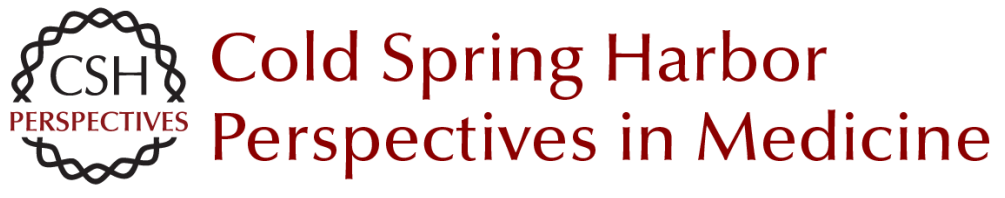

\title{
Ethanol Effects on N-Methyl-d-Aspartate Receptors in the Bed Nucleus of the Stria Terminalis
}

\author{
Tiffany A. Wills and Danny G. Winder
}

Cold Spring Harb Perspect Med 2013; doi: 10.1101/cshperspect.a012161 originally published online February 20, 2013

\section{Subject Collection Addiction}

Developments from Bulk Optogenetics to

Single-Cell Strategies to Dissect the Neural

Circuits that Underlie Aberrant Motivational States Jose Rodriguez-Romaguera, Vijay M.K. Namboodiri, Marcus L. Basiri, et al.

Consequences of Parental Opioid Exposure on Neurophysiology, Behavior, and Health in the Next Generations

Fair M. Vassoler and Mathieu E. Wimmer

Animal Models of the Behavioral Symptoms of Substance Use Disorders Louk J.M.J. Vanderschuren and Serge H. Ahmed

Translational Research in Nicotine Addiction Miranda L. Fisher, James R. Pauly, Brett Froeliger, et al.

Neonatal Opioid Withdrawal Syndrome (NOWS): A Transgenerational Echo of the Opioid Crisis Andrew E. Weller, Richard C. Crist, Benjamin C. Reiner, et al.

Impairment of Synaptic Plasticity by Cannabis, $\Delta^{\mathbf{9}}$ -THC, and Synthetic Cannabinoids Alexander F. Hoffman, Eun-Kyung Hwang and Carl R. Lupica

Drug-Evoked Synaptic Plasticity of Excitatory Transmission in the Ventral Tegmental Area Camilla Bellone, Michael Loureiro and Christian Lüscher

Opioid-Induced Molecular and Cellular Plasticity of Ventral Tegmental Area Dopamine Neurons Marie A. Doyle and Michelle S. Mazei-Robison
The Persistent Challenge of Developing Addiction

Pharmacotherapies

Sarah E. Swinford-Jackson, Charles P. O'Brien,

Paul J. Kenny, et al.

Opioid Modulation of the Gut-Brain Axis in Opioid-Associated Comorbidities

Li Zhang and Sabita Roy

Epigenetics of Drug Addiction Andrew F. Stewart, Sasha L. Fulton and lan Maze

Genetic Vulnerability to Opioid Addiction Brian Reed and Mary Jeanne Kreek

Glutamatergic Systems and Memory Mechanisms Underlying Opioid Addiction Jasper A. Heinsbroek, Taco J. De Vries and Jamie Peters

Mechanisms of Nicotine Addiction Marina R. Picciotto and Paul J. Kenny

Neural Substrates and Circuits of Drug Addiction Matthew W. Feltenstein, Ronald E. See and Rita A. Fuchs

The Role of the Central Amygdala in Alcohol Dependence Marisa Roberto, Dean Kirson and Sophia Khom

For additional articles in this collection, see http://perspectivesinmedicine.cshlp.org/cgi/collection/ 